\title{
THE PAPER-MAKING PROPERTIES OF PHORMIUM TENAX (NEW ZEALAND FLAX)
}

\author{
By Merle B. Shaw, George W. Bicking, and Martin J. O'Leary
}

\section{ABSTRACT}

Experimental tests were made at the bureau to ascertain the suitability of phormium tenax (New Zealand flax) fiber for paper manufacture.

Phormium tenax is a plant of the lily family native to New Zealand, where it grows luxuriantly under a wide range of conditions. It is cultivated to only a limited extent, but reports state that if the demand warranted it would be produced on a large scale, sufficient for commercial consideration for paper making. At present it is used principally for cordage, but it does not withstand well the alternations of wetness and dryness to which rope is frequently subjected, and therefore has not competed very successfully with other cordage materials.

Three representative samples-unscutched, scutched, and tow-were employed in the tests. Experimental papers were made on buth laboratory and senicommercial scale.

In a number of the tests the preparation of the pulp included two successive cooking operations, fractional digestion. Fither the caustic-soda process or the 2-stage cooks using sodium sulphite and caustic soda, respectively, gave very good results, on the basis of both quality of fiber produced and yleld obtained.

The tests indicate that phormium is a promising material for the mallufacture of wrapping or writing papers, but that the fiber must be thoroughly cleaned mechanically before being submitted to the paper-making processes. The scutched material showed the best possibilities.

Data are given relative to the kind and amount of chemicals used in the cooking liquor, yield of unbleached pulp, bleaching quality of the pulp, and physical and chemical properties of the papers made.

\section{CONTENTS}

I. Introduction

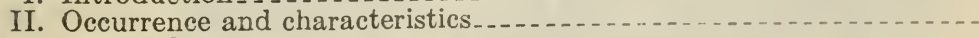

1. General

2. Test samples........... 413

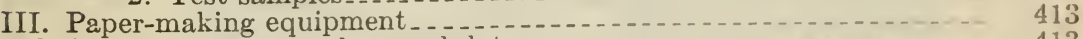

IV. Experimental procedure and data . . . . . . . . . . . . . . . 413

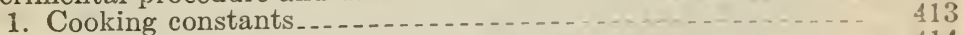

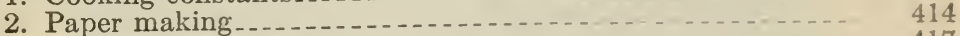

(a) Laboratory .

(1) Unscutched fiber................... 417

(2) Scutched fiber ..................... 417

(b) Semicommercial ....................... 41 ?

(1) Unscutched fiber ................ 419

(2) Scutched fiber _............... 419

(3) Tow

3. Fiber measurements

\section{INTRODUCTION}

Experimental paper-making tests have recently been made at the National Bureau of Standards to ascertain the suitability of phormium tenax (New Zealand flax) fiber for paper manufacture. The tests were 
made in cooperation with the New Zealand department of scientific and industrial research. The increasing consumption of pulp and paper products and the gradual diminution of the supply of raw materials commonly used in their manufacture make such potential sources of paper-making fiber of considerable interest. The data obtained, together with comments and discussion, are, therefore, reported here for the general information of the paper industry.

\section{OCCURRENCE AND CHARACTERISTICS}

\section{GENERAL 1}

Phormium fiber is obtained from the leaves of phormium tenax, a native plant of New Zealand. It was for a long time commonly known in the market as New Zealand flax. The term is misleading, however-flax belonging to the Linacex family, phormium to the Liliacea-therefore the correct name, phormium, is now more
generally applied.

Phormium tenax growing under virgin conditions has a range in altitude from sea level to perhaps 4,000 feet. It is distributed in both swamps and hillsides, but light rich soil by the side of rivers and brooks is best suited to its cultivation as a commercial crop. It is propagated from seeds or from division of the rootstock.

The plant has no upright stem. A creeping stem, or rootstock, spreads horizontally beneath the surface of the soil, and from it grow narrow, sword-shaped leaves, from 2 to 4 inches wide and from 4 to 8 feet long, arranged in fan-shaped clusters similar to those of the iris or garden flag. (See fig. 1.)

Considered with reference to the portion of the plant from which they are derived, vegetable fibers may be classed as seed fibers (such as cotton) growing from the seeds of the plant, stem fibers (such as flax, jute, and ramie) growing in the bast of dicotyledonous plants, and leaf fibers (which include manila, sisal, and phormium) occurring in the leaf tissues of monocotyledonous plants.

Although stem fibers are known commercially as soft fibers and leaf fibers as hard, phormium is rather soft, and with extra care in preparation may be spun and woven into cloth resembling linen duck. Its principal use is for cordage at the present time, however, either alone or in combination with manila, which it resembles in appearance. It is said to be suitable for binder twine, but it does not withstand well the alternations of wetness and dryness to which ropes are frequently subjected and, therefore, has not competed very successfully with
other cordage materials.

In the normal preparation of the fiber the leaves are fed into a stripping machine which beats off the bulk of the green nonfibrous tissue, and the fiber is passed to the washing machines where most of the loose vegetable matter remaining is washed away. The washed fiber is formed into hanks and hung over poles outdoors to dry and to be bleached by exposure to the weather. The dried material at this stage constitutes the commercial unscutched fiber.

If the fiber is to be further refined it is next scutched to remove any dry vegetation adhering. The short, broken fiber separated in the scutching process is recovered and is marketed as tow.

1 The botanical information was obtained from New Zealand department of agriculture Bulletin No. 95, Phormium tenax, by E. H. Atkinson; 1922 . The economic data were supplied by E. Marsden, secretary,
New Zealand department of scientiflc and industrial research. 


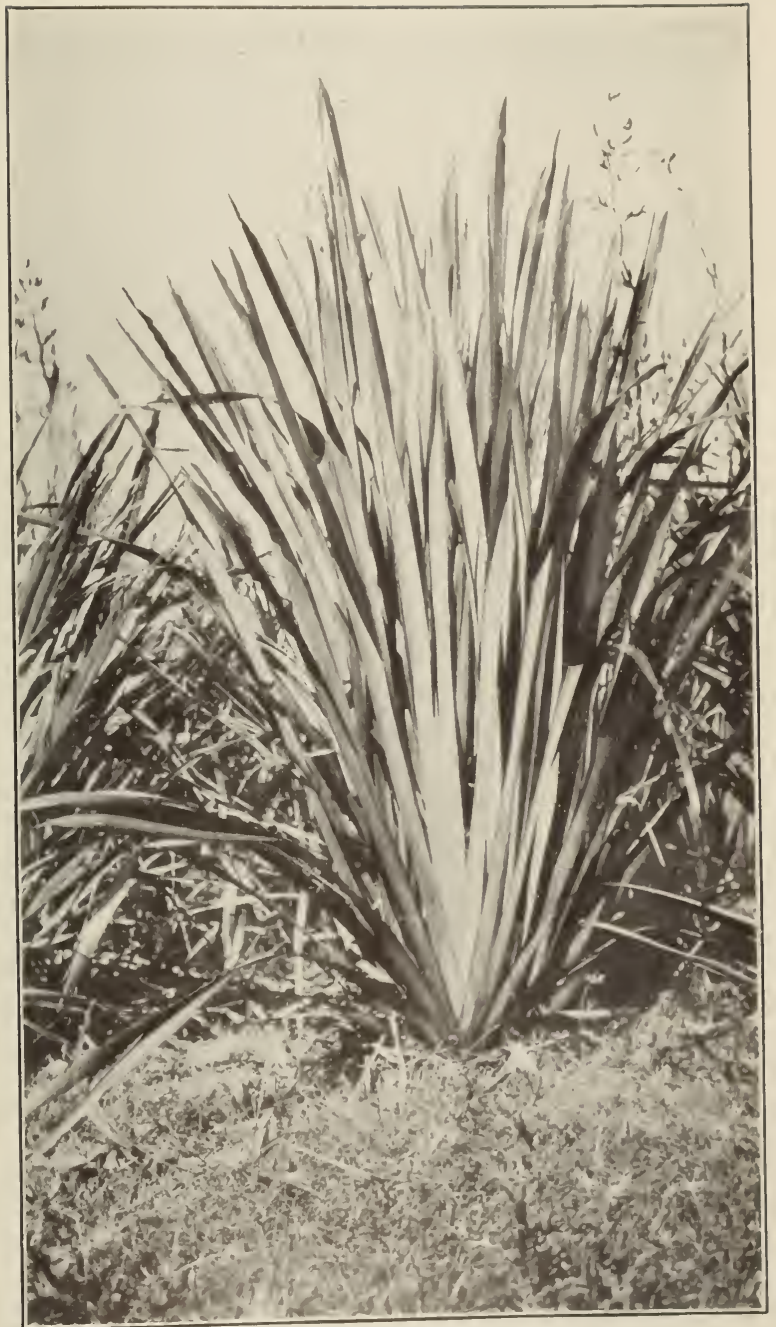

Figure 1.- 1 phormium tenax plant 
In order to be of commercial value for paper making, fiber must not only be suitable for such use, but also be available in large quantity, more or less constant, and at a low cost. At present approximately only 25,000 tons of phormium are exported annually, and the cost of the fiber prepared for cordage manufacture is about $\$ 100$ per ton; but reports state that if the demand warranted the plant could be cultivated on a large scale, sufficient for commercial consideration, and that the present cost of production, which is now chiefly labor costs, would be very considerably reduced, since mechanical harvesters and conveyors and improved methods of refining would then be worth while.

\section{TEST SAMPLES}

Three different samples of phormium were employed in the papermaking tests. The samples were designated as unscutched, scutched, and tow, and were representative of the fiber at the corresponding stages of preparation. The material was supplied by the New Zealand department of scientific and industrial research.

\section{PAPER-MAKING EQUIPMENT}

The tests were made on both laboratory and semicommercial scale. The laboratory equipment used in the preparation of the pulp and its subsequent conversion into paper consisted of a small rotary boiler; one-half pound beater (capacity one-half pound of dry fiber), fibersheet mold, sheet press, and sheet dryer. The equipment is used at the bureau for the laboratory paper-making tests of all materials under investigation and has been fully described and illustrated in previous bureau publications. ${ }^{2}$

The equipment of the bureau paper mill is adapted for making paper on a semicommercial scale under practical mill conditions. The equipment employed in the phormium tests was that in general use in the mill and consisted of a rag duster; rag cutter; rotary boiler; 50-pound copper-lined wood-tub beater, having manganese-bronze bars and plate, and equipped with a washing cylinder; Jordan refiner, with bars of a bronze and steel alloy; 4-plate screen; and 29-inch Fourdrinier paper-making machine, with wire 33 fect long and having two presses, nine 15-inch dryers, a small machine stack of seven rolls, and a reel. ${ }^{3}$

\section{EXPERIMENTAL PROCEDURE AND DATA}

\section{COOKING CONSTANTS}

The kinds and amounts of chemical solvents employed in the boiling solutions to dissolve the noncellulose material and soften the paper-making fiber are shown in Table 1. As will be noted, in a number of the tests the phormium was cooked twice, fractionally digested, the spent liquor from the first digestion loeing drained off

${ }^{2}$ Merle B. Shaw, George W. Bicking, and Len W. Snyder, The Preparation of Fiber Test Sheets, Paper Trade J., 90, No. 16, pp. 60-66; A pr. 17, 1230; also, B. S. Jour. Research, 5, pp. 105-114; July, 1930. Merle B. Shaw, Equipment and Research of the Bureau of Standards Paper Mill, Paper Trade J., s9, No. 19, pp. $60-63$; Nov. $7,1929$.

a Photographs of equipment are shown in B. S. Tech. Psper No. 340, Carós Fiber as a Papor-Making Material, pp. 338-341; also Equipment and Research Work of the Bureau of Standards Paper Mili, Puper Trade J., 89, No. 19, pp. 60-63; Nov. 7, $192 \%$. 
after the completion of that operation and fresh solution being added for the next, The constant factors were in general as follows:

Laboratory:

Weight of bone-dry material

Volume of water.

Cooking temperature

Cooking pressure.

Time for raising to cooking temperature _..... . . . _. . . . _ hour..

Duration of cooking temperature

Time for cooling

Semicommercial:

Weight of bone-dry fiber.......

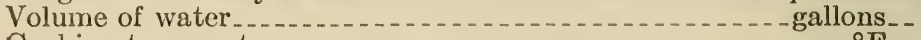

Cooking temperature

Cooking pressure

Time for raising to cooking temperature _. . . . . . _.... hour.

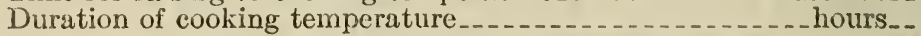

\section{PAPER MAKING}

The table gives data relative to the stage of refinement of the phormium when received (scutched, unscutched, or tow), chemicals used in the cooking liquor, yield of unbleached pulp, bleaching quality of the pulp, and measurements on the physical and chemical properties of the papers made. The percentage of chemical used in cooking is based on the bone-dry weight of the fiber furnished to the boiler; the yield of pulp is on the air-dry basis. Bleaching tests were made on samples of most of the pulps. The quantity of bleaching powder employed is expressed in terms of the bone-dry weight of the cooked and washed fiber. The laboratory sheets were made from unbleached pulp; whereas with two exceptions-runs Nos. 809 and 810 - the semicommercial runs were on bleached stock. Further description of the individual tests follows. 


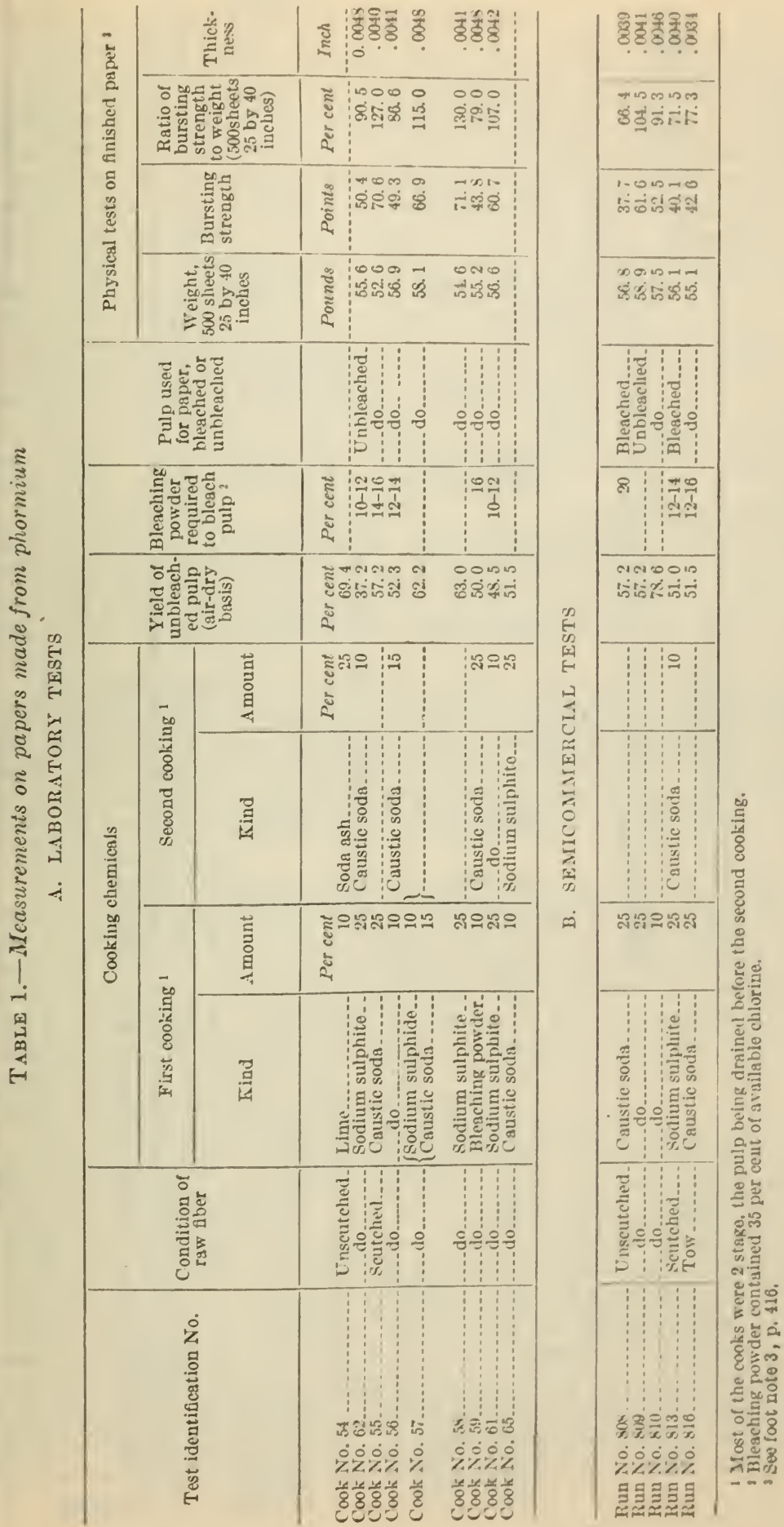




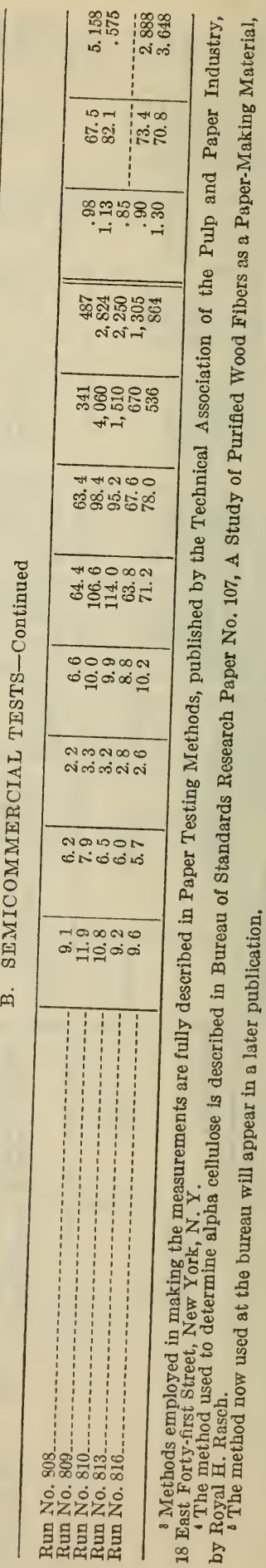


(a) LABORATORY

(1) Unscutched fiber.-Paper-making pulp was prepared from the unscutched phormium by two successive cooking operations. As previously stated, after completion of the first stage of the cooks, the liquor was drained off, the fresh solution was added, and the operation was continued. Cook No. 54 was with 10 per cent of lime and 25 per cent of soda ash, respectively. The resultant pulp was raw and appeared not to have received drastic enough chemical treatment. A small beater of stock was prepared from it, however, and made into sheets, but the paper was not sufficiently satisfactory to justify making the physical and chemical tests.

For cook No. 62 the phormium was first threshed and dusted. The fiber loss in these operations was approximately 10 per cent. The cooking chemicals were sodium sulphite and caustic soda. The yield of pulp was 41.3 per cent, based on the weight of fiber furnished to the boiler, or 37.2 per cent if expressed in terms of the weight of the phormium before it was threshed or dusted.

(2) Scutched fiber.-Cooks Nos. 55 and 56 were both with 25 per cent of caustic soda, but for No. 56, 10 per cent was used first and the cooking repeated with 15 per cent. The pulps bleached satisfactorily and the fibers were fairly clean. Neither the pulp nor the finished paper for cook No. 56 seemed any better, however, than for cook No. 55.

The cooking solution for No. 57 was a mixture of sodium sulphide and caustic soda. The pulp could not be bleached satisfactorily, and the paper made was, therefore, suitable only for wrapping or similar uses. Perhaps, the amount of caustic soda added should not have been decreased-should have been 25 per cent, as in cook No. 55but the results obtained were not sufficiently promising to warrant making such a cook.

For the next cook (No. 58), 25 per cent of sodium sulphite was used. The resultant pulp did not bleach satisfactorily on account of the presence of unreduced woody sections, but it was the cleanest and the best in color of any of the pulps thus far obtained. The papers made from this cook and from No. 57 were somewhat leathery in appearance. As shown in the table, they were high in tearing resistance, and had good folding endurance. Possibly part of the resins, gums, pectins, etc., were not removed in the boiling and acted as binding or cementing material.

The phormium of cook No. 59 was first treated with 10 per cent of bleaching powder. At this stage the fiber was warmed, but was not raised to the temperature of the other cooks. The cooking constants were followed otherwise. It was thought that perhaps the lignin would be resolved by the bleach, and consequently a cleaner and better pulp would ba obtained in the subsequent caustic-soda process; but the pulp did not bleach as well as that of cook No. 55, in which caustic soda only was used. The color of the bleached fiber was dead, not bright as the other pulps had been. The reaction of the lime in the bleach liquor with the lignin may have formed products which were insoluble in the caustic soda solution and, therefore, not removed in the second cook. Treating the phormium with chlorine gas instead of bleaching liquor before boiling it with caustic soda. 
might be more satisfactory; but since the cooks that were made with sodium sulphite showed the most promising results, it was thought that any additional tests should be concentrated along that line. The strength of the paper made was less than that from the other cooks. The high ash content was doubtless due to lime from the bleaching treatment.

The next cook (No. 61) was first made with 25 per cent of sodium sulphite and then with 10 per cent of caustic soda (16 per cent if based on the approximate weight of the pulp after the sulphite cooking). The pulp was very clean, and the paper made from the unbleached stock was of good quality.

When sodium sulphite was used in the previous fractional digestions, it was used in the first stage. The order was reversed in cook No. 65. The yield of pulp by this latter procedure compared favorably with that obtained in the other cooks, but the color of the unbleached pulp was not nearly so good.

Following the completion of the other laboratory and the semicommercial tests, supplementary tests were made using a treatment with weak alkali at comparatively low temperature as the first stage of the fractional digestion.

W. Raitt, of the Forest Research Institute, Dehra Dun, India, has for several years been working on an inexpensive and satisfactory method for converting bamboo into a good pulp. In order to whiten the pulp obtained by the usual cooking methods, a large amount of bleach was necessary. Raitt found during the course of his experiments that by first treating the bamboo with a weak alkali solution at comparatively low temperatures and then with stronger caustic at higher temperatures most of the bleaching difficulties were overcome. $\mathrm{He}$ discovered that the trouble was not inherent in the fiber or the incrusting lignin, but was in the type of pectin present. He found that pectins are easily soluble at the lower temperature, but that the transformation products combine with soda at the higher temperatures to produce a dark brown solution of great staining power, which is absorbed by the cellulose in the digester and requires for removal bleaching so severe as to be destructive of fiber. ${ }^{4}$

The method used by Raitt was believed to be equally well suited to other grasses and was that applied in the supplementary tests on phormium.

To extract and eliminate the starch and pectuous constituents before the phormium was broken down into fiber; that is, before the lignin was removed, the phormium was first treated with a weak solution of caustic soda, 0.85 per cent (10 per cent if based on weight of phormium), at $200^{\circ}$ to $210^{\circ} \mathrm{F}$. This digestion was followed by boiling with a solution of $2 \frac{1}{2}$ per cent (30 per cent if based on original weight) caustic soda at $340^{\circ} \mathrm{F}$. The pulp produced was less deeply stained and bleached with approximately 10 per cent of bleaching powder, but the final product differed little from that obtained by fractional digestion with sodium sulphite and caustic soda.

- W. Raitt, The Bamboo Hope, Procs. Technical Section, Papermakers' Association of Great Britain and Ireland, pp. 89-101; October, 1927. Abstracted in Paper Trade J., 85, No. 16, pp. 48-50; Oct. 20, 1927. The Fractional Digestion of $13 a m b o o$ and other Grasses Producing Annual Culms, pp. $331-341$ of Modern Paper Making, by Clapperton and Henderson, 1929; Ernest Benn (Ltd.), Bouverie House, Fleet Street, E, C, 4, London, 
B. S. Journal of Research, RP285

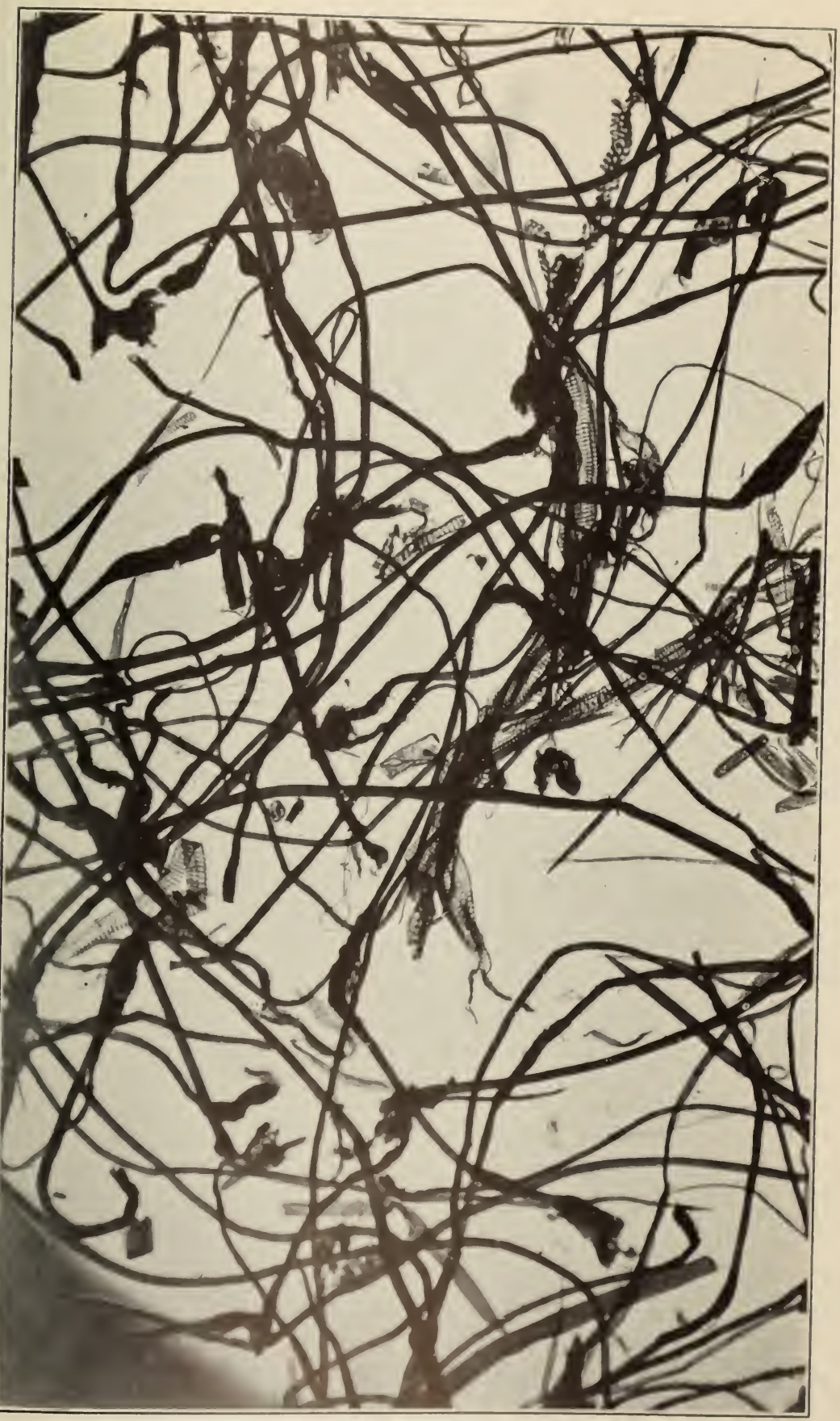

Figtre 2.-I Pormumm lenax filsei. ; 100 


\section{(b) SEMICOMMERCIAL}

(1) Unscutched fiber.-A cook was made with 25 per cent of caustic soda. One-half of the resultant pulp was washed, bleached, and converted into paper in run No. 808. The stock on the paper machine was "slow," but caused no trouble. When leaving the presses the paper seemed to be very tough and strong, but after going vver the dryers it was somewhat brittle and had lost much of its strength. Apparently the nonfibrous constituents were not all removed in the cooking, washing, and bleaching operations, and when subjected to the heat of the dryers made the paper brittle. Viewed in the microscope the fiber's of the stock looked very clean, but evidently they needed to be purified more.

Run No. 809 was on the remaining half of the cook, but the pulp was not bleached. As for run No. S0S, the paper appeared promising when leaving the presses but lost strength and became brittle when dried.

Run No. 810 was wrapping paper, unbleached. The stock did not screen satisfactorily through screen plates with either 0.024 or 0.036 inch slots. Apparently the nonfibrous materials not removed in the cooking were the cause of the difficulty. The stock was finally run out without being screened. The loss of strength of the paper in drying described in the preceding runs was also experienced here.

(2) Scutched fiber.-For the scutched fiber sodium sulphite was used in the first digestion stage and caustic soda in the second. No trouble was experienced in the run and the resultant paper was of good quality.

(3) Tow.-Run No. 816 was with tow, the coarse and broken part of the phormium separated in the process of cleaning, cooked with 25 per cent of caustic soda.

The chemical test data reported in the table were not available at the time the paper runs were being made, therefore several changes that it is now evident should have been made were not included. The low alpha cellulose content indicates that the purification of the pulp was insufficient. The high copper numbers indicate that the pulps were overbleached, or, perhaps, that impurities not eliminated in the cooking and washing processes reacted with the bleach, and that the resultant products were not removed in the subsequent washing operation. At the time run No. 808 was made the pulp was believed to be overbleached.

\section{FIBER MEASUREMENTS}

Figure 2 is a photomicrograph ${ }^{5}$ of unbleached scutched phormium fiber. The figure shows the fibers to be long and narrow with pointed ends, somewhat like linen in appearance, but more smooth and without markings.

The length of the fiber varies from 1.63 to $4.37 \mathrm{~mm}$, and the diameter from 0.006 to $0.020 \mathrm{~mm}$. The following fiber measurements afford comparison of phormium with other paper-making fibers.

3 Photomicrograph and phormium fiber measurements were made by Mary L. Rollins, of this bureau; dimensions of other fibers were taken from standard textbooks. 


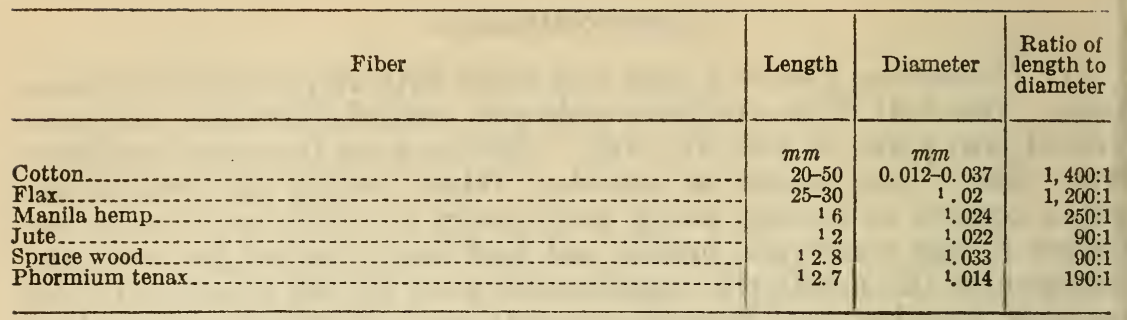

1 Average.

\section{CONCLUSIONS}

From the results obtained in the tests it is appsrent that phormium needs to be thoroughly cleaned mechanically before being submitted to paper-making processes. The scutched material, that from which the greatest amount of the nonfibrous tissue has been removed previous to being marketed, has the best possibilities. Additional mechanical cleaning is required in the paper mill, however, preparatory to the pulping operation. A method suggested is that the phormium be passed through a machine to loosen it; placed upon conveyors of wire screening, for sorters to pick out weeds, roots, dead plants, etc., that may have escaped removal at time of preparation; and dusted to remove all remaining fine foreign material, such as fruit seeds, sand, etc., before being cut into desired lengths for boiling.

The best digestion procedure depends somewhat upon mill conditions. In the work at the bureau either the caustic soda process or the two-stage cooks using sodium sulphite and caustic soda, respectively, gave very good results, on the basis of both quality of fiber produced and yield obtained. No special equipment is required for the caustic-soda process; whereas when sodium sulphite is employed, the boiler should be of an acid-resistant material. An ordinary iron rotary boiler was used at the bureau, but considerable trouble was caused by iron rust from the sodium sulphite digestion. The process is believed to be very promising, however.

The experimental tests indicate that phormium is a promising material for the manufacture of wrapping or writing papers.

Washington, January 13, 1931. 